\title{
Knowledge of Human Papillomavirus, Risk of Anogenital Cancers, and Benefits of Vaccination: A Medical Student Survey in Saudi Arabia
}

Salman N. Almutairi ${ }^{1}$, Abullah A. Aljalfan ${ }^{2}$, Zuhour A. Alqahtani ${ }^{1}$, Asem M. Shadid ${ }^{1}$, SalahUd-Din Khan ${ }^{3}$

1. Miscellaneous, Imam Mohammad Ibn Saud Islamic University, Riyadh, SAU 2. Miscellaneous, Imam Muhammed Ibn Saud Islamic University, Riyadh, SAU 3. Biochemistry, College of Medicine, Imam Mohammad Ibn Saud Islamic University, Riyadh, SAU

$\square$ Corresponding author: Salman N. Almutairi, salman.almutairi.97@gmail.com Disclosures can be found in Additional Information at the end of the article

\section{Abstract}

\section{Background}

Human papillomavirus (HPV) is one of the most common sexually transmitted infections and plays a significant role in the development of anogenital cancer. However, there is a lack of awareness on the subject in Saudi Arabia and very few documented studies on the knowledge and awareness of medical students regarding HPV.

\section{Methods}

A cross-sectional study utilizing a survey distributed to 306 medical students of both genders was utilized. A self-administrated questionnaire was distributed to all participants to assess their knowledge of HPV and their attitude towards HPV vaccination. Data analysis was performed using SPSS v 24 (IBM Corp., Armonk, NY, US) and RStudio v 1.14 (Boston, US).

\section{Results}

Most of the respondents (72.2\%) had a high level of knowledge regarding HPV, with $47.84 \%$ of the respondents being aware of the risks associated with HPV and having a positive attitude towards HPV. Female respondents had better awareness and knowledge as compared to male students. However, there was a lack of knowledge regarding the duration and frequency of HPV infection, which could have an effect on the attitude of medical students towards vaccination. The results obtained by using Pearson's correlation coefficient showed a statistically significant correlation between the attitude towards HPV and the knowledge regarding HPV (p-value <

Received 05/12/2019 Review began 05/23/2019 Review ended 06/30/2019 Published 07/01/2019

\section{(C) Copyright 2019}

Almutairi et al. This is an open access article distributed under the terms of the Creative Commons Attribution License CC-BY 3.0., which permits unrestricted use, distribution, and reproduction in any medium, provided the original author and source are credited. 0.05).

\section{Conclusion}

Better awareness and knowledge regarding HPV and its risks correlate with a better attitude towards HPV. The medical school curriculum was found to be a primary source of information for students on the awareness of HPV. Therefore, more about HPV and the benefits associated with vaccination against HPV should be included in the curriculum in all years of medical school.

\section{How to cite this article}

Almutairi S N, Aljalfan A A, Alqahtani Z A, et al. (July 01, 2019) Knowledge of Human Papillomavirus, Risk of Anogenital Cancers, and Benefits of Vaccination: A Medical Student Survey in Saudi Arabia. Cureus 11(7): e5051. DOI 10.7759/cureus.5051 
Categories: Infectious Disease, Oncology

Keywords: hpv, cancer, saudi arabia, medical students, vaccination

\section{Introduction}

Human papillomavirus (HPV) is a common infecting agent, with certain high-risk types (HPV 16 and 18) that predispose men and women of varying ages to cancers such as anogenital (cervical, anal, and penile cancer) in addition to a subset of head and neck, particularly oropharyngeal, squamous cell carcinomas. The low-risk types (HPV 6 and 11) result in benign conditions such as warts [1-2]. The method of HPV transmission includes sexual intercourse and from the mother to her newborn during labor [3]. After infection, the virus could remain asymptomatic for years and the infection could clear on its own, but sometimes, the infection persists and progresses to cervical cancer. HPV infection is known to be the primary cause of cervical cancer in more than $70 \%$ of the total cervical cancer cases [4].

Cervical cancer is a major sequela of HPV infection, culpable for more than 311,000 deaths and 570,000 new patients per year [5]. Considering the fact that, at one point, the HPV burden accounted for $5.2 \%$ of the cancer load worldwide, the idea of vaccinating against HPV is equivalent to vaccinating against cancer [2], demonstrated by the decreasing prevalence of cervical cancer to 13,240 new cases per year, with a death toll of 4170 cases in a developed country such as USA [6]. While in contrast, $85 \%$ of the death toll from cervical cancer occurs in developing nations due to limited access to preventative measures [5]. HPV vaccination is estimated to decrease the incidence of cervical cancer by $42 \%-51 \%$ and reduce the mortality by $34 \%-45 \%[7]$.

Prophylactic vaccinations for high-risk HPV types are available, have been shown to be immunogenic, safe, and effective in the primary prevention of certain cancers and have an application window from 11-26 years [8].

A major issue faced against HPV vaccinations includes the lack of awareness about available options for vaccination and the negative attitude towards vaccination from the general public and healthcare professionals alike. Since medical students of today will be the practicing doctors of tomorrow, a need to assess their knowledge, attitude, and willingness to utilize HPV vaccination by including it as an essential addition to the vaccination regimen in children to protect them from preventable incidences of cancer [9].

While similar studies have been conducted worldwide, no studies have been reported on both male and female students from Riyadh, to assess the presumed advancement of the awareness of medical students from preclinical to clinical years. This study aims to fill this gap of knowledge and assess the level of knowledge between genders and their respective attitudes. We also attempt to gain an understanding of the possibility and the need for addressing the issue by including necessary changes in the medical school curriculum.

\section{Materials And Methods}

\section{Ethical approval, study design, and instruments}

This cross-sectional study was conducted at a University in Riyadh, Saudi Arabia. The institutional review board approved the research protocol for the present study (0036/05/201854). The data were collected using a validated and self-administrated questionnaire adapted and modified from a previous study, with a reliability study Cronbach alpha value of 0.7.

\section{Sampling method and size}


This study utilized the convenience-sampling method. The Raosoft calculator was used to calculate the sample size with a $5 \%$ margin of error and a $95 \%$ confidence level. Based on the above, the minimum sample size required for this study was 235 , and 306 medical students eventually participated. The study population included male and female medical students from the first to the fifth years, with the first to third years being basic sciences years and the fourth and fifth being clinical sciences years. The study had an equal percentage of students representing each academic year (20\%).

The only inclusion criterion was students studying the bachelor of medicine and surgery program at the university. The participants were given a study information sheet and an informed consent form, along with a survey questionnaire. Participants were informed that their anonymity and confidentiality would be maintained, and they could withdraw from the survey at any time.

\section{Data analysis}

The data analysis was performed using SPSS v 24 (IBM Corp., Armonk, NY, US) and R studio v 1.14 (Boston, US). Categorical data were summarized as counts and percentages. The questionnaire used was divided into four main sections:

1. Four questions to assess the participants' demographics

2. Seventeen questions to assess the participants' knowledge of the subject

3. Twelve questions to assess the participants' attitudes toward HPV

4. A checkbox question to assess the source of information on HPV

\section{Descriptive statistics}

Descriptive statistics were performed to assess the number of respondents who answered each question correctly. The percentage of correct responses for each participant was calculated. The level of knowledge of the respondents was categorized based on the total score for the correct answers, with one mark for each correct answer, and the maximum score was 17 . The categories included the high (12-17), moderate (6-11), and low (0-5) levels of knowledge. The mean knowledge score was also calculated. Attitudes towards HPV were assessed using a five-point Likert scale ranging from strongly agree to strongly disagree. Respondents' attitudes were classified into positive (3.68-5), neutral (2.34-3.67), and negative (1-2.33) based on the total score.

\section{Inferential statistics}

Pearson's correlation coefficient was used to determine the correlation between knowledge and the attitude toward HPV and cervical cancer. A p-value of less than 0.05 was considered statistically significant.

\section{Results}

\section{Descriptive statistics}

Males accounted for $69 \%(n=211)$ of the study sample while females accounted for $31 \%(n=95)$. Most of the participants were aged 18-25 ( $n=289$; 94.4\%). All academic years were equally presented in the study sample (20\% per each year), making the sample representative of the whole population and allowing for comparisons between groups. Most of the participants were 


\section{Cureus}

unmarried ( $\mathrm{n}=294,96.1 \%)$, as shown in Table 1 . The reliability of the questions addressing the attitude of participants was 0.75 (>0.7), which is considered acceptable.

\begin{tabular}{|c|c|c|}
\hline & Level & Count (\%) \\
\hline \multirow[t]{2}{*}{ Gender (\%) } & Female & 95 (31.0) \\
\hline & Male & $211(69.0)$ \\
\hline \multirow[t]{2}{*}{ Age (\%) } & $18-25$ & $289(94.4)$ \\
\hline & $>25$ & $17(5.6)$ \\
\hline \multirow[t]{5}{*}{ Academic year (\%) } & 1st year & $60(19.6)$ \\
\hline & 2nd year & $61(19.9)$ \\
\hline & 3rd year & 63 (20.6) \\
\hline & 4th year & $61(19.9)$ \\
\hline & 5th year & $61(19.9)$ \\
\hline \multirow[t]{3}{*}{ Marital status (\%) } & Single & $294(96.1)$ \\
\hline & Married & $6(2.0)$ \\
\hline & Other & $6(2.0)$ \\
\hline
\end{tabular}

TABLE 1: Descriptive statistics for the study sample $(n=306)$

\section{Attitudes toward HPV}

Results show that most participants were aware of the severity of HPV (92\%). The majority (81\%) were also aware of the fact that HPV is preventable and that the vaccine against HPV can prevent cervical cancer (83\%). Responses were not consistent for Question 5, as only about half of the respondents (42\%) thought that they were susceptible to HPV while the remaining did not (58\%). Most participants thought that the HPV vaccine was safe (82\%), and a high proportion (78\%) thought that there was a lower risk associated with prevention (vaccination) than with infection.

Likewise, responses to Questions 7 through 12 show that participants have positive attitudes toward HPV prevention. The proportion of participants that agreed or strongly agreed to these questions exceeded 70\%, except for Question 8 (vaccinating young people against HPV would not encourage them to become sexually active). Approximately half of the respondents agreed (55\%) while the rest (45\%) disagreed with the above statement.

The majority of the respondents showed a positive attitude towards HPV and were well aware of its risks $(n=177,47.84 \%)$. The remaining respondents were neutral $(n=128,41.83 \%)$ and only one respondent had a negative attitude toward HPV, as shown in Table 2. 


\section{Cureus}

\begin{tabular}{|c|c|c|c|c|c|c|c|c|c|c|}
\hline & \multicolumn{2}{|l|}{ SD } & \multicolumn{2}{|l|}{ D } & \multicolumn{2}{|l|}{$\mathbf{N}$} & \multicolumn{2}{|l|}{ A } & \multicolumn{2}{|c|}{ SA } \\
\hline & $\mathrm{n}$ & $\%$ & $\mathrm{n}$ & $\%$ & $\mathrm{n}$ & $\%$ & $\mathrm{n}$ & $\%$ & $\mathrm{~N}$ & $\%$ \\
\hline 1. Cervical cancer is a severe disease. & 1 & $0.3 \%$ & 5 & $1.6 \%$ & 34 & $11.1 \%$ & 121 & $39.5 \%$ & 145 & $47.4 \%$ \\
\hline 2. Cervical cancer is preventable. & 2 & $0.7 \%$ & 17 & $5.6 \%$ & 77 & $25.2 \%$ & 114 & $37.3 \%$ & 96 & $31.4 \%$ \\
\hline $\begin{array}{l}\text { 3. HPV vaccine is helpful to prevent cervical } \\
\text { cancer. }\end{array}$ & 4 & $1.3 \%$ & 10 & $3.3 \%$ & 74 & $24.2 \%$ & 116 & $37.9 \%$ & 102 & $33.3 \%$ \\
\hline 4. I am susceptible to HPV infection. & 71 & $23.2 \%$ & 60 & $19.6 \%$ & 95 & $31.0 \%$ & 48 & $15.7 \%$ & 32 & $10.5 \%$ \\
\hline 5. HPV vaccine is safe. & 1 & $0.3 \%$ & 10 & $3.3 \%$ & 90 & $29.4 \%$ & 117 & $38.2 \%$ & 88 & $28.8 \%$ \\
\hline $\begin{array}{l}\text { 6. There is less risk involved in being vaccinated } \\
\text { than having HPV infection. }\end{array}$ & 8 & $2.6 \%$ & 11 & $3.6 \%$ & 95 & $31.0 \%$ & 106 & $34.6 \%$ & 86 & $28.1 \%$ \\
\hline $\begin{array}{l}\text { 7. HPV vaccination will not lead to complicated } \\
\text { sexual activities. }\end{array}$ & 17 & $5.6 \%$ & 30 & $9.8 \%$ & 93 & $30.4 \%$ & 98 & $32.0 \%$ & 68 & $22.2 \%$ \\
\hline $\begin{array}{l}\text { 8. Vaccinating young people against HPV would not } \\
\text { encourage them to become sexually active. }\end{array}$ & 32 & $10.5 \%$ & 60 & $19.6 \%$ & 93 & $30.4 \%$ & 72 & $23.5 \%$ & 49 & $16.0 \%$ \\
\hline $\begin{array}{l}\text { 9. I would not want my children to be infected with } \\
\text { HPV. }\end{array}$ & 5 & $1.6 \%$ & 12 & $3.9 \%$ & 50 & $16.3 \%$ & 52 & $17.0 \%$ & 187 & $61.1 \%$ \\
\hline $\begin{array}{l}\text { 10.Information on HPV helps me to decide whether } \\
\text { my children should be vaccinated against HPV }\end{array}$ & 4 & $1.3 \%$ & 12 & $3.9 \%$ & 74 & $24.2 \%$ & 85 & $27.8 \%$ & 131 & $42.8 \%$ \\
\hline $\begin{array}{l}\text { 11.If my doctor thinks HPV vaccination is a good } \\
\text { idea, I would have my children vaccinated }\end{array}$ & 5 & $1.6 \%$ & 16 & $5.2 \%$ & 72 & $23.5 \%$ & 95 & $31.0 \%$ & 118 & $38.6 \%$ \\
\hline 12. I would have vaccinated against HPV if the & 5 & $1.6 \%$ & 23 & $7.5 \%$ & 97 & $31.7 \%$ & 83 & $27.1 \%$ & 98 & $32.0 \%$ \\
\hline
\end{tabular}

\section{TABLE 2: Attitude of medical students towards human papillomavirus}

HPV: human papillomavirus, SD: strongly disagree, D: disagree, N: neutral, A: agree, SA: strongly agree

\section{Knowledge regarding HPV}

Results show that the percentage of correct answers ranged from $34.31 \%$ for Question 9 to 83.66\% for Questions 2 and 11. Question 9 scored the lowest (HPV infection can resolve spontaneously), which indicates a serious lack of knowledge regarding HPV infection and management and can affect the attitude of medical students toward vaccination. Questions 2 (HPV infections are preventable) and 11 (HPV can cause genital warts) scored highest, with $83.66 \%$ of the participants answering each of these two questions correctly, as shown in Table 3. 


\section{Cureus}

\begin{tabular}{|c|c|c|}
\hline & Question & $\mathbf{N}(\%)$ \\
\hline Q1 & HPV can cause cervical cancer? & $246(80.4)$ \\
\hline Q2 & HPV infections are preventable? & $256(83.7)$ \\
\hline Q3 & Condom use can prevent HPV infection? & $20 /(6 / .6)$ \\
\hline Q4 & $\mathrm{HPV}$ is a sexually transmitted disease (STD)? & $252(82.4)$ \\
\hline Q5 & HPV infection is frequent? & $1 / 2(56.2)$ \\
\hline Q6 & HPV infection can last for years? & $235(76.8)$ \\
\hline Q7 & Cervical cancer is caused by persistent HPV infection? & $242(79.1)$ \\
\hline Q8 & HPV may infect both, men and women? & $248(81.0)$ \\
\hline Q9 & Most HPV infection resolves spontaneously? & $105(34.3)$ \\
\hline Q10 & HPV can infect you without symptoms? & $219(71.6)$ \\
\hline Q11 & HPV can cause genital warts? & 256 (83.7) \\
\hline Q12 & HPV can cause other anogenital cancers (e.g. penis, anus and cervical)? & $224(73.2)$ \\
\hline Q13 & HPV vaccine prevents around $70 \%$ of cervical cancer? & $229(74.8)$ \\
\hline Q14 & Pap-smear can screen cervical cancer? & $253(82.7)$ \\
\hline Q15 & Pap-smear is very or relatively effective in screening cervical cancer? & $239(78.1)$ \\
\hline Q16 & Pap-smear should be done every 3 years? & $199(65.0)$ \\
\hline Q17 & Pap-smear can be done after the age of $21 ?$ & $227(74.2)$ \\
\hline Score Mean (SD) & & $12.45(3.30)$ \\
\hline \multicolumn{3}{|l|}{ Knowledge (\%) } \\
\hline & Low & $15(4.9)$ \\
\hline & Medium & $70(22.9)$ \\
\hline & High & $221(72.2)$ \\
\hline
\end{tabular}

TABLE 3: Knowledge of HPV and cervical cancer across participants $(n=306)$

HPV: human papillomavirus, Q: question

Knowledge regarding HPV was high among the participants, where only 15 (4.9\%) had a low level of knowledge (score $<5)$ and only $70(22.9 \%)$ had moderate knowledge. A majority ( $\mathrm{n}=221$, $72.2 \%$ ) had a high level of knowledge. The mean knowledge score was 12.45 (3.3).

\section{Correlation between attitude and knowledge regarding HPV}




\section{Cureus}

There was a statistically significant correlation between attitudes towards HPV and knowledge regarding HPV ( $\mathrm{r}=0.31, \mathrm{P}<0.001$ using Pearson's correlation), indicating that the participants who have a positive attitude toward HPV also have high knowledge regarding HPV and its risks.

\section{Knowledge Source}

The medical curriculum was the source of information for $45.1 \%$ of the students while selflearning was a source of knowledge for $33.99 \%$ of the students. However, $27.45 \%$ of the students did not remember the source and only 3.92\% obtained their knowledge from awareness campaigns, as shown in Figure 1.

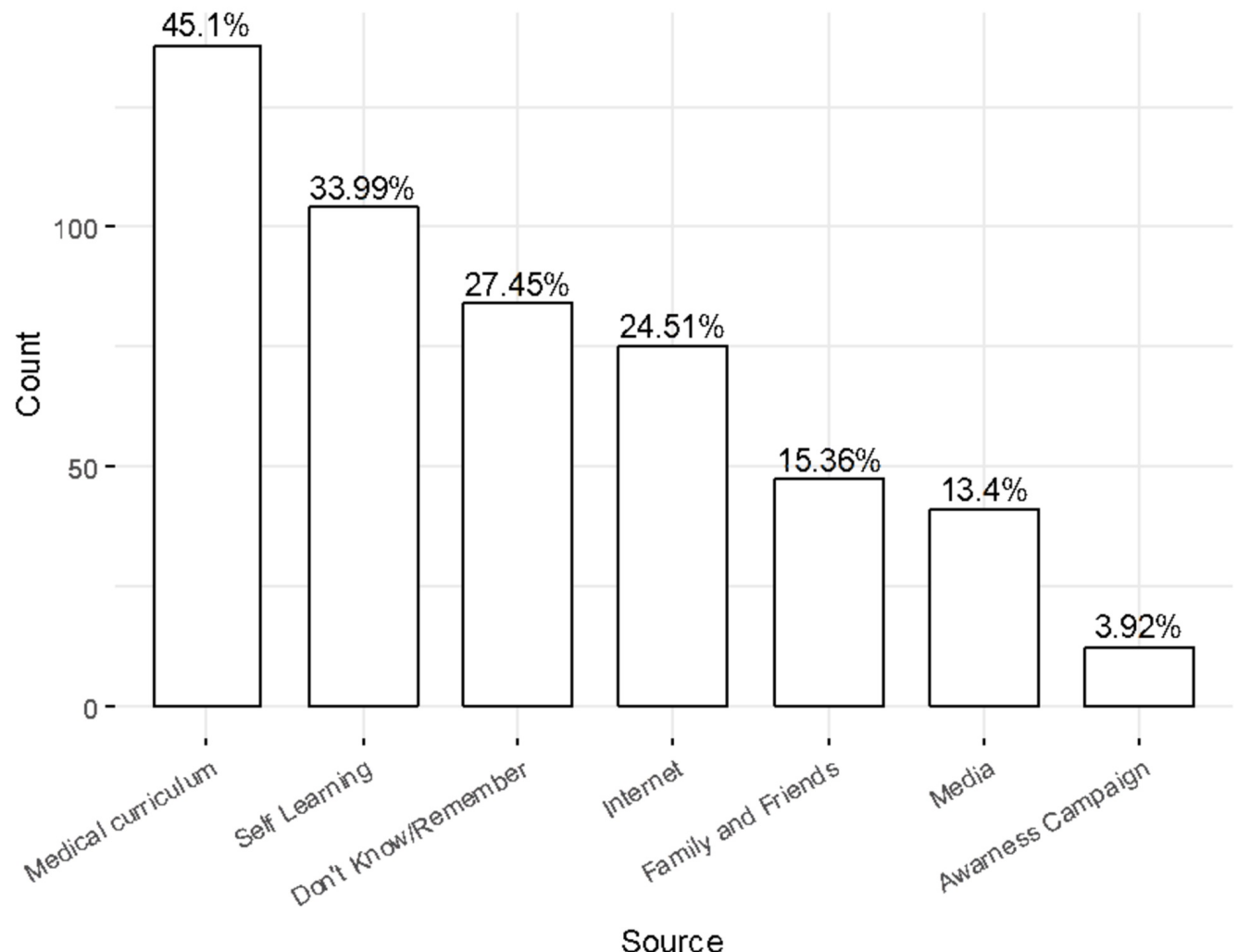

\section{FIGURE 1: Source of information}

Interestingly, $82.61 \%$ of the students who mentioned the medical curriculum as their main source of information had a high level of knowledge in comparison to $61.7 \%$ of students who mentioned family and friends as their source of information on HPV. Likewise, $83.65 \%$ of students who mentioned self-learning as their main source of information had a high level of knowledge on the subject.

\section{Association of demographics with knowledge score}

The result shows that the mean knowledge score was significantly higher in females as compared to males $(13.25$ vs. 12.09 , $\mathrm{p}<0.001)$. Neither age nor academic year was significantly associated with knowledge score ( $\mathrm{p}=0.341$ and 0.126 , respectively), as shown in Table 4. 


\section{Cureus}

\begin{tabular}{|c|c|c|c|c|}
\hline & & \multicolumn{2}{|c|}{ Knowledge score } & \multirow[b]{2}{*}{$\mathrm{P}$} \\
\hline & & Mean & SD & \\
\hline \multirow{2}{*}{ Gender } & Female & 13.25 & 1.99 & \multirow{2}{*}{$<0.001^{*}$} \\
\hline & Male & 12.09 & 3.69 & \\
\hline \multirow{2}{*}{ Age } & $18-25$ & 12.49 & 3.30 & \multirow{2}{*}{0.341} \\
\hline & $>25$ & 11.71 & 3.41 & \\
\hline \multirow{5}{*}{ Academic year } & 1st & 12.52 & 2.40 & \multirow{5}{*}{0.126} \\
\hline & 2nd & 12.49 & 3.31 & \\
\hline & $3 r d$ & 12.54 & 3.59 & \\
\hline & 4th & 11.41 & 3.79 & \\
\hline & 5th & 13.28 & 3.05 & \\
\hline
\end{tabular}

TABLE 4: Knowledge score based on age, gender, and academic year

\section{Knowledge regarding HPV based on gender}

There was a statistically significant difference in the knowledge between males and females $(\mathrm{P}=0.028)$. None of the females had low knowledge as compared to $7.11 \%(\mathrm{n}=15)$ of males, who scored low on knowledge of HPV. The proportion of females with moderate and high knowledge was also higher than the male students ( $24.2 \%$ and $75.8 \%$ vs. $22.3 \%$ and $70.6 \%$, respectively).

\section{Discussion}

The demographic data indicate a male majority in the sample population, attributed to the fact that the chosen academic institute had female students only from the first to third academic years. As results have elaborated, female students were more knowledgeable of HPV, with 75\% of them having high knowledge and none having poor knowledge of HPV, which is in agreement with previously reported findings [1,10-11].

High level of knowledge in this student population is an important finding, as HPV vaccination specifically targets this age group [11]. As this age group is considered to be most susceptible to contracting serious malignant illness from HPV infection, it is all the more relevant, as the knowledge of female participants has a direct relationship with women's health.

With almost half of the students attributing the medical curriculum as their main source of knowledge regarding HPV, the finding also emphasizes the importance of including allimportant information within the curriculum itself. Additionally, as one-third of the students cited self-learning as their source of knowledge, it is evident that the medical curriculum was not comprehensive and students felt the need to seek knowledge about the subject of HPV from other sources. 
Although age and academic year were not relevant with respect to the extent of knowledge regarding HPV, there was an increment in knowledge among the students in the fifth year, suggesting that the exposure to health information of female patients and medical conditions in the obstetrician/gynecologist (OB/GYN) curriculum contributed to additional information on the subject. Overall, the level of knowledge was high among students, where $72.2 \%$ were highly knowledgeable regarding HPV, contradictory to the literature reports, where students were shown to have moderate to poor knowledge about HPV [11-14].

Our study indicates that there is an improvement in medical student's awareness concerning HPV in the surveyed Saudi university. According to our findings, better knowledge regarding HPV and its risks was associated with a better attitude toward HPV vaccination, which has been shown in other studies as well [11-14].

The student's attitude toward HPV vaccination informs us about the likelihood of these future doctors passing on the information regarding vaccination to their patients [15-17]. Based on this, we assessed our participant's attitude and found near-consensus about the preventability of HPV infections and the safety of the vaccination and an overall high level of awareness regarding HPV infections. However, one of the areas where their awareness was lacking included their own susceptibility to the infections, with $58 \%$ of the respondents believing that they were not in danger of contracting HPV.

Evidently, the greater majority proved to be inclined to vaccinate their kids, if their doctors thought it to be suitable, exemplifying the importance of a doctor's role in raising awareness. In addition, they themselves would get vaccinated if the vaccine was readily and freely available, which is also in agreement with findings previously reported in the literature [11-14].

The Malaysian government offers a free vaccination program, where all 13-year-old girls receive three doses of the vaccination [18]. Saudi Arabia offers the vaccination in its major hospital free of charge or for a designated fee [19]. This may act as an incentive for people to get vaccinated if they are informed and educated on the availability of the vaccine.

The study shows that the respondents were overall very knowledgeable, with $83.66 \%$ knowing that HPV is preventable and it leads to genital warts. Of the respondents, $80.4 \%$ were aware that HPV could cause cervical cancer, which is clinically important, as $89 \%$ of cervical cancer cases in Saudi Arabia are linked to HPV infection, with a prevalence rate that is comparable to the international prevalence rate [19].

Almost half of the surveyed students did not know that HPV infection is frequent, and twothirds of the respondents were unaware that HPV infection could resolve spontaneously, indicating a lack of understanding of the duration and frequency of HPV infection and its tendency to regress. The correlation between the level of knowledge and the source of information proved that students who were more inclined toward self-learning had a higher level of knowledge (83.65\%), closely followed by those who learned from their medical curriculum (82.61\%), emphasizing the need to draft a medical curriculum that incorporates all the necessary information for the students. Students who cited family, friends, and other people from their social circles as a source of knowledge proved to be the least knowledgeable, which exemplifies the need to raise awareness within the society and among medical students with regards to HPV virus and infections.

\section{Limitations}

One of the limitations of the present study is that it has been conducted at a single medical college. This college only recently started admitting female students and at the time of this 
study, the medical college had female students only up to the third academic year.

\section{Conclusions}

In conclusion, the mean knowledge score regarding HPV is higher in female medical students as compared to males. There was no relationship between age and academic year regarding the extent of knowledge about HPV. A better attitude towards HPV correlates with better knowledge of HPV and its risks.

Early improvements in education can help future doctors treat and decrease the incidence of HPV by imparting comprehensive information on the risks of HPV transmission as well as preventive measures to all years of the medical school curriculum, as students largely depend on their curriculum as a primary source of information on HPV. More effective awareness programs need to be introduced to educate the general public about the risks associated with HPV and the benefits of the HPV vaccine.

\section{Additional Information \\ Disclosures}

Human subjects: Consent was obtained by all participants in this study. Imam Muhammed Ibn Saud Islamic University issued approval 0036/05/2018-54. The subjects were provided a consent form and a self-administered questionnaire when enrolled into the study. Animal subjects: All authors have confirmed that this study did not involve animal subjects or tissue. Conflicts of interest: In compliance with the ICMJE uniform disclosure form, all authors declare the following: Payment/services info: All authors have declared that no financial support was received from any organization for the submitted work. Financial relationships: All authors have declared that they have no financial relationships at present or within the previous three years with any organizations that might have an interest in the submitted work. Other relationships: All authors have declared that there are no other relationships or activities that could appear to have influenced the submitted work.

\section{References}

1. Rajiah K, Maharajan M, Fang Num KS, How Koh RC: Knowledge about human papillomavirus and cervical cancer: predictors of HPV vaccination among dental students [Internet]. Asian Pac J Cancer Prev. 6:1573-1579. 10.22034/APJCP.2017.18.6.1573

2. Armstrong DKB, Handley JM: Anogenital warts in prepubertal children: pathogenesis, HPV typing and management. Int J STD AIDS. 1997, 8:78-81. 10.1258/0956462971919598

3. Wang CJ, Palefsky JM: Human papillomavirus (HPV) infections and the importance of HPV vaccination. Curr Epidemiol Rep. 2015, 2:101-109. 10.1007/s40471-015-0039-3

4. Hoots BE, Palefsky JM, Pimenta JM, Smith JS: Human papillomavirus type distribution in anal cancer and anal intraepithelial lesions. Int J Cancer. 2009, 124:2375-2383. 10.1002/ijc.24215

5. Human papillomavirus (HPV) and cervical cancer . (2019). Accessed: 8/6/2019: https://www.who.int/news-room/fact-sheets/detail/human-papillomavirus-(hpv)-andcervical-cancer.

6. Siegel R, Miller K, Jemal A: Cancer statistics. CA Cancer J Clin. 2018, 68:7-30. 10.3322/caac. 21442

7. Harper DM, Franco EL, Wheeler C, et al.: Efficacy of a bivalent L1 virus-like particle vaccine in prevention of infection with human papillomavirus types 16 and 18 in young women: a randomised controlled trial. Lancet. 2004, 9447:1757-1765. 10.1016/S0140-6736(04)17398-4

8. Hall M, Simms K, Lew J, Smith M, Saville M, Canfell K: Projected future impact of HPV vaccination and primary HPV screening on cervical cancer rates from 2017-2035: example from Australia. Plos One. 2018, 13:0185332. 10.1371/journal.pone.0185332

9. Gari A, Asiri A, Mohammed A, et al.: The awareness of the HPV's association with cervical cancer and the HPV vaccine among Saudi females. Life Sci J. 2012, 9:2538-2546. 
10. Ngorsuraches S, Nawanukool K, Petcharamanee K, Poopantrakool U: Parents' preferences and willingness-to-pay for human papilloma virus vaccines in Thailand. J Pharm Policy Pract. 2015, 8:20. 10.1186/s40545-015-0040-8

11. Rajiah K, Mari Kannan M, Nang S, Num K: Awareness and acceptance of human papillomavirus vaccination among health sciences students in Malaysia. VirusDisease. 2015, 26:297-303. 10.1007/s13337-015-0287-3

12. Maharajan MK, Rajiah K, Num KSF, Yong NJ: Knowledge of human papillomavirus infection, cervical cancer and willingness to pay for cervical cancer vaccination among ethnically diverse medical students in Malaysia. Asian Pac J Cancer Prev. 2015, 16:5733-5739.

10.7314/apjcp.2015.16.14.5733

13. Maharajan MK, Rajiah K, Fang KNS, Lui LY: Cervical cancer prevention in Malaysia: knowledge and attitude of undergraduate pharmacy students towards human papillomavirus infection, screening and vaccination in Malaysia. J Cancer Educ. 2017, 32:166-174. 10.1007/s13187-015-0957-2

14. Yacobi E, Tennant C, Ferrante J, Pal N, Roetzheim R: University students' knowledge and awareness of HPV. Prev Med. 1999, 28:535-541. 10.1006/pmed.1999.0486

15. Ko EM, Missmer S, Johnson NR: Physician attitudes and practice toward human papillomavirus vaccination. J Low Genit Tract Dis. 2010, 14:339-345. 10.1097/LGT.0b013e3181dca59c

16. Soon R, Dela Cruz MR, Tsark JU, Chen JJ, Braun KL: A survey of physicians' attitudes and practices about the human papillomavirus (HPV) vaccine in Hawai'i. Hawaii J Med Public Health. 2015, 74:234-241.

17. Strohl A, Mendoza G, Ghant M, Cameron KA, Simon MA, Schink JC, Marsh EE: Barriers to prevention: knowledge of HPV, cervical cancer, and HPV vaccinations among African American women. Am J Obstet Gynecol. 2015, 212:65-71. 10.1016/j.ajog.2014.06.059

18. Ezat SWP, Hod R, Mustafa J, Dali M, Hatta AZ, Suraya SA, Azlin A: National HPV immunisation programme: knowledge and acceptance of mothers attending an obstetrics clinic at a teaching hospital, Kuala Lumpur. Asian Pac J Cancer Prev. 2013, 14:2991-2999. 10.7314/APJCP.2013.14.5.2991

19. Alsbeih G: HPV infection in cervical and other cancers in Saudi Arabia: implication for prevention and vaccination. Front Oncol. 2014, 65:3978341. 10.3389/fonc.2014.00065 